\title{
EL PENTECOSTALISMO Y LA \\ TOMA DE TIERRAS EN CERRO \\ DE PASCO (1958-1967)
}

\section{Gerson Francisco Julcarima Álvarez}

\section{E.}

A Serafín Nieto Chamorro, único y gran biógrafo de los primeros pentecostales de la provincia de Daniel Alcides Carrión (departamento de Pasco).

A Paulo Barrera Rivera y Héctor Laporta, por la entrega generosa de sus apreciaciones críticas y conocimientos.

CASI TODO LO QUE A CONTINUACIÓN expondré se funda esencialmente en la labor encomiable de Serafín Nieto Chamorro, personaje que se encargó en 1997 de registrar las biografías de los primeros líderes pentecostales de Cerro de Pasco. Los infortunios de mi vida me han impedido hasta la fecha conocerlo personalmente, pero igual lo aprecio, a pesar de que sólo conozca de él su obra denominada Historia del evangelio en la Quebrada de Chaupihuaranga (provincia Daniel Alcides Carrión), departamento de Pasco. 


\section{LA ANTESALA: UNA LIMITACIÓN Y UNA PRECISIÓN}

Quizá por esta razón deba reconocer que mis reflexiones tienen una limitación estrechamente relacionada con la desventura de no haber podido hasta la fecha confrontar algunas conclusiones mías con los sujetos investigados en el presente estudio.

También quiero precisar que sé que mi opción por el uso de las metodologías cualitativas en este trabajo despertará las apreciaciones críticas que esta tradición sociológica ha sabido granjearse. Respecto de esta situación, pienso que quizá el punto más discutible es "la posibilidad de generalización" a partir de la biografía o de la historia de vida, ante lo cual sólo tengo que sugerir que, si bien es cierto la biografía se constituye en un fragmento de la totalidad, ésta nos permite -también- acceder a dicha generalidad. En otras palabras, soy consciente de que cada biografía representa en última instancia la especificidad de la vida de un sujeto, pero creo también que en esa especificidad uno puede hallar rasgos de la estructura social, por esta razón creo -al igual que Reséndiz García- que la generalización es válida cuando uno ha ubicado la presencia y operación de la estructura social y sus nexos con la individualidad ${ }^{1}$.

\section{LA HIPÓTESIS NULA, LA INTERROGANTE Y LA TÉCNICA DE INVESTIGACIÓN}

Mi interés por desarrollar la temática surgió cuando me enteré de que ciertos líderes de las comunidades religiosas pentecostales participaron en la toma masiva de tierras acaecida en Cerro de Pasco entre los años de 1956 y $1963^{2}$. Al tener certeza de este hecho, me

1 Una más detallada y prolija exposición acerca de la biografía como método de investigación social la pueden encontrar en un articulo de Reséndiz García bajo el titulo "Biografía: proceso y nudos teórico-metodológicos", publicado en María Luisa Tarrés (coordinadora), Observar, escuchar y comprender: Sobre la tradición cualitativa en la investigación social, Ciudad de México, FLACSO, 2001.

2 Serafín Nieto ha registrado la participación de los líderes pentecostales Agapito Robles Broncano (Yanacocha), Teófilo Torres Espinoza (Michivilca) y Augusto Roque Espinoza (Páucar), así como también la participación de algunos feligreses como Héctor Gutiérrez, Octavio Crispín y Epifanio Quintana. 


\section{EL PENTECOSTALISMO Y LA TOMA DE TIERRAS EN CERRO DE PASCO}

pregunté al instante sobre las razones que habrían llevado a estos feligreses pentecostales a involucrase en dicho movimiento social. Luego mi interés aumentó cuando constaté que las tomas de tierras protagonizadas por los comuneros de Paucar, de Yanahuanca y Yanacocha, y de Michivilca (todas en la circunscripción de la provincia de Daniel Alcides Carrión -Pasco- y con participación de algún feligrés pentecostal) eran consideradas por Kapsoli ${ }^{3}$ como parte de la fase política violenta del movimiento campesino en Cerro de Pasco. Esto último debido a los grados de violencia y represión de dichos acontecimientos.

Para tales efectos, y debido al carácter exploratorio de mi investigación, decidí guiar el análisis con la hipótesis nula que dice así: "Toda religión no católica (popularmente llamada secta) contribuye a la indiferencia social y al apoliticismo de sus integrantes". Siendo la hipótesis nula desde el principio, entonces el análisis no buscaría validarla sino hallar las razones que expliquen su invalidez en este caso específico. De esta manera, siguiendo esta hipótesis, me aboqué a encontrar algunas premisas que explicaran por qué "los comuneros pentecostales no se mantuvieron al margen del movimiento de toma de tierras". En otras palabras, y como interrogante, lo que buscaba era responderme ¿por qué participaron en el proceso de toma de tierras personajes que, supuestamente, debido a su confesión religiosa -siguiendo nuestra hipótesis nula-, debieron haber desarrollado una actitud de indiferencia?

Resuelto el asunto de la hipótesis y la pregunta, pensé en la técnica de investigación ideal para el análisis. Este ejercicio no me tomó mucho tiempo, pues pronto advertí, al revisar algunos trabajos sobre los procesos de toma de tierras ${ }^{4}$, que mi perspectiva ana-

3 Además de esta acotación, el lector podrá ubicar una descripción pormenorizada de las tomas de tierras mencionadas en Wilfredo Kapsoli Escudero, Movimientos campesinos en Cerro de Pasco 1800-1963, Huancayo, Instituto de Estudios Andinos, 1975.

4 Me refiero a los trabajos de Howard Handelman, Struggle in The Andes Peasant Political Movilziation in Peru, Texas, University of Texas Press, 1975: Héctor Martínez, Las comunidades de Pasco y Junín: Informe preliminar, Lima, Instituto Indigenista, 1962; Rodrigo Montoya, Lucha por la tierra: reformas agrarias y capitalismo en el Perú del siglo XX, Lima, Mosca Azul, 1989; y Virginia Vargas, El campe- 
lítica y la temática planteada eran al parecer novedosas, así que terminé por convencerme de que las únicas bases donde podía sostener algunas reflexiones eran en ios registros biográficos desarrollados por Serafín Nieto y, como colofón, habría de hacer uso de la técnica llamada en la investigación social biografía o historia de vida.

\section{PRIMERAS IMPRESIONES Y ATISBOS EXPLICATIVOS}

Serafín Nieto me ha dejado saber a lo largo de su pormenorizada obra algunas citas reveladoras que prefiero reproducirlas, sabiendo que no existe otra forma de preservar su riqueza interpretativa:

"Ser algún día verdaderamente libres, y trabajar sus propias tierras para beneficio de ellos mismos, era la esperanza de los campesinos. Esa esperanza, aunque lejana, era alimentada cada día... Es allí cuando Dios levanta al hermano Agapito Robles Broncazo (...) y al hermano Teófilo Torres Espinoza (...)"

"O sea, el campesino tenía doble patrón: primero, el patrón tenia doble patrón, el patrón hacendado hombre y el patrón del pueblo, un ídolo de yeso o madera. Pero ninguno de esos se preocupaba de dar educación y libertad al hombre, tampoco por otorgarles libre uso de las tierras que legalmente les pertenecían. En esas condiciones era urgente y necesario que Dios obrara a través de un hombre para predicar el evangelio y así aprender y obtener la doble libertad que se necesitaba...".

"La presencia del evangelio fue como el sol radiante de la mañana, que iluminó la conciencia de los pobladores. Por ellos, muchos llegaron a ser protagonistas de acciones concretas (...). Por ejemplo, cuando se tuvieron que reivindicar nuestras tierras del poder de los patrones para que cada campesino las usara legítimamente".

sino en la historia: cronología de los movimientos campesinos 1956-1964, Lima, Ideas, 1981. 
"Abordamos la forma como ha cambiado el evangelio a miles de personas que estaban sumidas en la ignorancia, en la dominación y explotación de dioses terrenales, los patrones hacendados. Éstos, los patrones hacendados, se habían apoderado de las tierras, la conciencia, los hijos, las fuerzas de los pobladores de las comunidades, en alianza con los católicos romanos que los obligaban a celebrar las fiestas patronales. Allí, los comuneros se endeudaban y se comprometían a pagar con trabajos forzosos, durante años, a los hacendados prestamistas".

Teniendo en mente estas citas procuré indagar en la vida de Agapito Robles, hallando que no es sino hasta el año de 1958, dos años después de su conversión, que él participa como personero legal de su comunidad y, por lo tanto, se involucra en el proceso reivindicativo. Esta posición -según propio testimonio- le permite ver de cerca las amenazas y abusos que cometían los hacendados con los comuneros. Paulo Barrera en alguna charla me había sugerido que intentara algún acercamiento analítico diferente (y que me excuse si es que no logro reproducirlo exactamente), en el sentido de enfatizar que "la condición religiosa pentecostal" no explicaría en sí misma la participación de los comuneros en los "movimientos sociales"; en otras palabras, me invitaba a superar la visión bastante extendida, al interior de la comunidad académica evangélica, que argumentaba mecánicamente la participación política o social a partir de la fe religiosa. Entonces, siguiendo la vida de Agapito Robles, queda claro que la "constatación" de su posición social marginal lo lleva a emprender mecanismos destinados a revertir tal condición; inmediatamente, él forma el Frente Único de Ayllus en Lucha y decide organizar las comunidades para la toma de tierras, hecho que ocurre el 26 de agosto de 1963. Y ¿qué hay de su religiosidad fundamentalista?5. ¿Qué ocurre en el plano interno religioso?

5 Florencio Galindo, en su obra El protestantismo fundamentalista, ha querido ver en el pentecostalismo una expresión del fundamentalismo evangélico norteamericano, a pesar de que él mismo, en la obra en mención, ha reconocido que sus orígenes son marcadamente distintos y que incluso se pueden ubicar en la historia algunas relaciones conflictivas entre ambos movimientos. 
Al parecer, al interior del movimiento pentecostal se generó un discurso crítico, contestatario y efectivamente dinamizador que terminó no por guiar a toda la feligresía a ser parte de la movilización de la toma de tierras en Cerro de Pasco sino, más bien, les dejo la libertad de hacerlo, pues justificaba la eventualidad de que decidieran hacerlo. El solo reconocer este hecho nos lleva a distanciar el pentecostalismo del fundamentalismo evangélico. Así, me atrevo a afirmar que el pentecostalismo tiene como ingrediente característico una teología oral y pragmática en función a esta característica y, siempre mediados por su filtro religioso, los comuneros comprendieron su posición en la estructura social, dando como resultado que su incómoda situación era producto de una doble opresión maligna: la de la patrona del pueblo, que los inducía a la idolatría, y la de los hacendados, que no facilitaban escuelas para evitar que ellos tomaran conciencia y leyeran la Biblia 6 .

Como se ve, la elasticidad de su teología (oral), que se recrea sin parámetros fijos o temporales, respondiendo a ciertas condiciones inmediatas (pragmáticas) y acompañada de la recuperación de la autoestima, traducida como el tener el poder del Espíritu Santo, logró un discurso que posibilitó la acción social de los comuneros pentecostales en un determinado proceso político. Los líderes carismáticos más representativos, como Agapito Robles y Teófilo Robles, se encontraron con una lectura teológica que posibilitaba la

6 Quizá valga la pena señalar, por si le interesa al lector, que, para Carlos Iván Degregori, entre las décadas de 1920 y 1960, entre la mayoría del campesinado andino el mito del Inkarrí (la regeneración del incario) empezó a ser reemplazado por el mito del progreso, siendo una de las sendas para llegar a éste "el mito de la escuela", sobre lo cual Rodrigo Montoya ha recogido y relatado que "la ausencia de la escuela, el no saber leer o escribir, aparecen como sinónimos de oscuridad, noche (tuta); con la escuela y la alfabetización se hace la luz, llega el día (punchau)". Ambos comentarios se pueden ubicar más detalladamente en Sinesio López, Ciudadanos reales o imaginarios, p. 227. Sin duda, el imaginario campesino es bastante complejo, pero de haber existido efectivamente este elemento en la visión campesina andina (lo señalo debido a que Handelman ubica a los comuneros de Pasco como el campesinado socio-económicamente más avanzado de la sierra, pues tenían más contacto con el sector moderno urbano), creo que nuevamente la teología pentecostal (oral y práctica) en la construcción del discurso religioso incorporó y recreó, en respuesta a necesidades inmediatas, este elemento resaltado por Degregori y Montoya. 
participación en los movimientos de toma de tierras, que a la postre la historia ubicaría como reivindicativos y por tal -como señala Sinesio López- como una senda estratégica de construcción ciudadana de estos sectores marginados.

Ante la pregunta: ¿por qué participaron en el proceso de toma de tierras personajes que, supuestamente, debido a su confesión religiosa (protestante - pentecostal) debieron haber desarrollado otra actitud? Me permito insinuar una respuesta preliminar, fundada en el "discurso que se gestó en su interior", discurso posibilitado por lo que denomino teología oral y pragmática. David Martín, en otros términos, advirtió también que "el potencial de los pentecostales para actuar en forma adecuada según las necesidades de los miembros, en lugar de estar amarrados a una ideología concreta, constituía la filosofía social del movimiento" 7. Con esta primera apreciación satisfice, en parte, la duda que guió el análisis, pues al analizar las biografías de los primeros pentecostales noté que dos características más del movimiento saltaban a la vista: prácticas experimentales y liderazgos carismáticos, que pronto advertí como complementarios y necesarios para explicar la interrogante principal.

En efecto, al indagar en la vida de los primeros pentecostales de la provincia de Daniel Alcides Carrión (Cerro de Pasco), encontré un elemento siempre presente en las conversiones o adhesiones a la comunidad religiosa en mención. Teodoro Serrano (primer líder pentecostal en Daniel Alcides Carrión), Herminia Malpartida, Laura Lobatón, María Espinoza, entre otros, ubicaban su conversión en una práctica experimental: la sanidad. Este hecho me permite sostener que las prácticas experimentales (en especial la sanidad) son hitos fundantes en el proceso de identificación con la comunidad religiosa pentecostal. Aquí, de plano, el discurso religioso racionalizado como elemento de convencimiento en la conversión pasa a un segundo orden, lo importante es experimentar algún signo empírico, verificable por el individuo y por la comunidad religiosa para pasar a ser parte de la comunidad pentecostal. Por esta

7 David Martin, Tongues of fire: The explosion of protestantism in Latin America, Cambridge, Basil Blackwell, 1990, 108 pp. 


\section{GERSON FRANCISCO JULCARIMA ALVAREZ}

razón, las prácticas experimentales son elementos vitales en la liturgia pentecostal. Si bien es cierto que esta apreciación no responde directamente a la pregunta planteada en la investigación, por lo menos queda claro que la construcción de la identificación de los individuos con la comunidad religiosa pentecostal es fundada en una práctica experimental. Esta reflexión adquiere importancia cuando suponemos que, debido a que el proceso de identificación con la comunidad religiosa no responde a un proceso de convencimiento racional, terminamos por concluir que el proceso de interiorización de la doctrina no es fundamental en el proceso de identificación con el pentecostalismo. Esta última apreciación sostiene en parte nuestra respuesta preliminar, dado que nos ayuda a caracterizar a las comunidades pentecostales de Pasco como depositarias de una teología oral y pragmática. Llegado a este punto, no puedo dejar de señalar una pregunta inquietante que obviamente no busca ser respondida en el presente trabajo, pero que creo puede invitarnos a repensar nuestras caracterizaciones del movimiento pentecostal: ¿qué tan importante es la doctrina (entendida como un cuerpo de premisas lógicamente engarzadas) en las comunidades religiosas pentecostales?

Por òtro lado, Serafín Nieto señala que Teodoro Serrano empieza su labor proselitista en Daniel Alcides Carrión en 1947. Luego registra que en 1955 el movimiento pentecostal (bajo la denominación de Asamblea de $\operatorname{Dios}^{8}$ ) ya tenía en dicha zona una iglesia madre en Goyllarisquizga y cinco grupos pequeños en Chinche, Pillao, Tápuc, Chacayán y Shaguana. En 1956, debido a la labor

8 Deseo dejar constancia de que el movimiento pentecostal en el Perú está íntimamente ligado a la formación de las Asambleas de Dios del Perú (la denominación pentecostal más importante del Perú). Debido a divisiones al interior de esta organización, se forma posteriormente la Iglesia Pentecostal del Perú (la segunda denominación pentecostal en importancia). Luego de la creación de ambas organizaciones, han surgido varios grupos pentecostales de menor magnitud. También cabe acotar que posteriormente llegaron movimientos pentecostales más radicales, por ejemplo, la iglesia pentecostal "Dios es Amor", de procedencia brasileña. Finalmente, Rubén Zavala, en su obra Historia de las Asambleas de Dios (Lima 1989), ha señalado que la misión proselitista de las Asambleas de Dios empezó en 1922 en el Callao (Lima). 
proselitista de Hermenegildo Marcas, se registran tres pequeñas comunidades pentecostales más en los caseríos: Ocho de Diciembre, Charquicancha y Yanacocha. Al analizar los pormenores de estos "viajes misioneros", se puede observar la rápida constitución de liderazgos locales. Este hecho me reveló que el denominado liderazgo carismático es parte vital en la extensión del movimiento pentecostal en Pasco. En efecto, los liderazgos al interior de la comunidad pentecostal no son reclamados por razón de sucesión apostólica, por excelencia moral o méritos académicos, basta sólo el carisma, entendido como evidencia de acción divina. Por ejemplo, Teodoro Serrano era iletrado. Según sus datos biográficos, su aprendizaje de la Biblia se llevó a cabo por memorizaciones, pero esta situación no fue una limitación, más bien se convirtió en una virtud, debido a que la acción divina en su vida era visible. Douglas Petersen concluyó que "el movimiento difundió a tal punto la autoridad carismática que los pentecostales reconocían virtualmente cualquiera que pudiera reunir a un grupo de seguidores"9; así, tanto Bernardino Rojas (Charquicancha) como Conversión Robles (Yanacocha ) o Lorenzo Rojas (Ocho de Diciembre), en cuestión de días asumieron la responsabilidad de guiar a los nacientes grupos pentecostales en sus comunidades. Esta situación también refleja que la organización de las comunidades pentecostales dista mucho de ser rígida 0 burocratizada, en realidad, está en función del liderazgo carismático, permitiendo, de esta manera, una estructura bastante flexible y conectada en "red" a través del líder de cada grupo. Luther Gerlach, al respecto, ha señalado que "la versatilidad de dicho sistema desafía los intentos de racionalizar la organización, y en el proceso creó un sistema sumamente apto para el crecimiento exponencial y para promover o generar un cambio revolucionario"10. La última apreciación de Gerlach quizá deba ser entendida en el sentido de que dicha forma de organización, basada en la conexión de los grupos a partir de los liderazgos carismáticos (él también denomina a esta

9 Petersen Douglas, No con ejército ni con fuerza, Miami, Vida, 1996, p. 48.

10 Luther Gerlach, Pentecostalism: Revolution or Counter Revolution, Nueva Jersey, Princenton University Press, 1974, 680. 
estructura organizativa como policéfala), evidencia una plataforma eficaz para la movilización y difusión; en efecto, bajo este esquema bastaría con que los liderazgos difundan o coordinen acciones para obtener una respuesta masiva en toda la red de comunidades pentecostales. Nuevamente, esta característica no responde directamente nuestra interrogante, pero quizá nos insinúe que la difusión del discurso, dada la relación de los liderazgos carismáticos, posibilitó que varios comuneros pentecostales de Páucar ocuparan violentamente las tierras en conflicto con la hacienda Lauricoha, que los de de Yanacoha se movilizaran contra la hacienda Pomayarus y que los de Michivilca cooperaran en las movilizaciones violentas contra la familia Rispa (hacendados).

Dicho en pocas líneas, este caso ubicable en el tiempo y en el espacio me sirve para sostener que por lo menos tres características subyacentes del movimiento pentecostal: teología oral y pragmática, liderazgo carismático y practicas experimentales posibilitaron que el movimiento pentecostal desarrolle en su interior, en respuesta a su contexto social y político, un discurso -en este caso- crítico y justificador de una acción política determinada. A manera de generalizar mis apreciaciones, pienso también que, en otras circunstancias, en respuesta a otros contextos, estas mismas características del pentecostalismo quizá puedan desarrollar más bien discursos justificadores del status quo o de una posición de marginación social y política.

Quisiera concluir, siguiendo una reflexión de Carlos Franco plasmada en su brillante articulo "Sarita Colonia o los cholos invaden el Cielo", señalando que tal vez nuestros acercamientos al estudio de las expresiones religiosas populares se vean enriquecidos cuando aceptemos "la probabilidad de la existencia de un pluralismo de creencias y practicas religiosas, a pesar de ser parte de una misma tradición religiosa, surgidas del reconocimiento del poder de ese pueblo para producir el sentido de su experiencia religiosa o para reconocerse en la creación de sus propias teologías"11.

11 Franco, Carlos. La otra modernidad. Lima: CEDEP. 1991, p. 127. 